УДК 551.510.42:550.424(470.26)

РАСПРЕДЕЛЕНИЕ, ВЕЩЕСТВЕННЫЙ И ХИМИЧЕСКИЙ СОСТАВ

ОСАДОЧНОГО ВЕЩЕСТВА ДОЖДЯ, ПОСТУПАЮЩЕГО НА ТЕРРИТОРИЮ КАЛИНИНГРАДСКОЙ ОБЛАСТИ РФ

${ }^{1}$ Топчая В.Ю., ${ }^{1,2}$ Котова Е.И., ${ }^{1}$ Стародымова Д.П., ${ }^{1 Ч е ч к о ~ В . А . ~}$

${ }^{1}$ ФГБУН «Институт океанологии им. П.П. Шириова» Российской академии наук,

Москва, е-mail:piwis@mail.ru;

${ }^{2}$ Федеральный исследовательский центр комплексного изучения Арктики им. академика Н.П. Лаверова РАН, Архангельск

На окружающую среду Калининградской области большое влияние оказывает трансграничный атмосферный перенос антропогенных примесей, превышающий выбросы локальных источников эмиссий в 5-7 раз. Приведены результаты исследования количественного, вещественного и химического составов нерастворимых микрочастиц дождевых осадков. В рамках работы было собрано и обработано 29 проб дождевых осадков разных сезонов 2019 г. Определена концентрация нерастворимых микрочастиц в дождевой воде. Проведен анализ вещественного состава методом сканирующей электронной микроскопии. Содержание $\mathrm{Al}, \mathrm{Mn}, \mathrm{Ni}, \mathrm{Cu}, \mathrm{Zn}, \mathrm{Cr}, \mathrm{Co}, \mathrm{As}, \mathrm{Sr}, \mathrm{Cd}, \mathrm{Mo}, \mathrm{Ba}, \mathrm{V}$ и $\mathrm{Pb}$ определяли методом атомно-абсорбционной спектрофотометрии. Методом расчета коэффициента обогащения выявлена группа тяжелых металлов (Рb, $\mathrm{Cd}, \mathrm{Zn}, \mathrm{Cu}$ и Ni) антропогенного происхождения. Проведен корреляционный анализ, позволивший выделить две группы взаимосвязанных элементов. Определена значимая корреляционная связь между концентрациями $\mathrm{Al}, \mathrm{Mn}, \mathrm{Co}, \mathrm{Zn}, \mathrm{Sr}$ и $\mathrm{Ba}(\mathrm{R}=0,87-0,98)$, что подтверждает их литогенное происхождение. Вторая группа взаимосвязанных элементов $-\mathrm{Zn}, \mathrm{Cr}, \mathrm{Mo}$, As и $\mathrm{Pb}(\mathrm{R}=0,70-0,87)$, что указывает на их литогенное и антропогенное происхождение. Для выявления удаленных источников эмиссий, при помощи программы HYSPLIT рассчитаны обратные траектории переноса воздушных масс. Выявлена сезонная изменчивость в количественном распределении и вещественном составе микрочастиц дождей. Наиболее высокие значения концентрации (6,5-12,2 мг/л) и доминирование антропогенной компоненты в составе выявлены в дождях летне-осеннего периода, а наиболее низкие (1,1-3,9 мг/л), с преобладанием биогенной и минеральной компонент - для весеннего периода. Установлено, что на распределение и состав нерастворимых микрочастиц дождевых осадков Калининградской области РФ оказывают влияние как локальный, так и дальний атмосферный перенос.

Ключевые слова: дождь, элементный состав, тяжелые металлы, Калининградская область РФ, трансграничный атмосферный перенос

\title{
DISTRIBUTION, MATERIAL AND CHEMICAL COMPOSITION OF SEDIMENTARY MATTER OF RAINFALL ON THE TERRITORY OF THE KALININGRAD REGION RF
}

\author{
${ }^{1}$ Topchaya V.Yu., ${ }^{1,2}$ Kotova E.I., ${ }^{1}$ Starodymova D.P., ${ }^{1}$ Chechko V.A. \\ 'P.P. Shirshov`s Institute of Oceanology Russian Academy of Sciences, Moscow,e-mail: piwis@mail.ru; \\ ${ }^{2} N$. Laverov Federal Center for Integrated Arctic Research RAS, Arkhangelsk
}

The quantitative, material and chemical compositions of insoluble microparticles of rainfall was studied. As part of the work, 29 rainfall samples of different seasons of 2019 were collected and processed. The concentration of insoluble microparticles in rainwater was determined. The analysis of the material composition by scanning electron microscopy. The contents of $\mathrm{Al}, \mathrm{Mn}, \mathrm{Ni}, \mathrm{Cu}, \mathrm{Zn}, \mathrm{Cr}, \mathrm{Co}, \mathrm{As}, \mathrm{Sr}, \mathrm{Cd}, \mathrm{Mo}, \mathrm{Ba}, \mathrm{V}$, and $\mathrm{Pb}$ was determined by atomic absorption spectrophotometry. The method of calculating the enrichment coefficient revealed a group of heavy metals $(\mathrm{Pb}, \mathrm{Cd}, \mathrm{Zn}, \mathrm{Cu}$, and $\mathrm{Ni})$ of anthropogenic origin. As a result of correlation analysis, two groups of interconnected elements are distinguished. The first group of interrelated elements is $\mathrm{Al}, \mathrm{Mn}, \mathrm{Co}, \mathrm{Zn}, \mathrm{Sr}$ and $\mathrm{Ba}$ $(\mathrm{R}=0.87-0.98)$ was determined, which confirms their lithogenic origin. The second group of interrelated elements is $\mathrm{Zn}, \mathrm{Cr}, \mathrm{Mo}$, As and $\mathrm{Pb}(\mathrm{R}=0.70-0.87)$, which indicates their lithogenic and anthropogenic origin. To identify remote sources of emissions, using the HYSPLIT program, the reciprocal paths of air mass transfer are calculated. Seasonal variability in the quantitative distribution and material composition of rain microparticles was revealed. The highest concentration values $(6.5-12.2 \mathrm{mg} / \mathrm{l})$ and the dominance of the anthropogenic component in the composition were detected in rains of the summer-autumn period, and the lowest $(1.1-3.9 \mathrm{mg} / 1)$, with the predominance of the biogenic and mineral components, for the spring period. It has been established that the distribution and composition of insoluble microparticles of rainfall in the Kaliningrad region RF is influenced by both local and long-range atmospheric transport.

Keywords: rain, elemental composition, heavy metals, Kaliningrad region, transboundary atmospheric transport

Атмосферный перенос - наиболее динамичный, характеризующийся высокими скоростями, дальностью и изменчивостью направлений переноса путь поставки микрочастиц различного генезиса, в том числе и на подстилающую поверхность. Оседающие антропогенные микрочастицы с содержащимися на них тяжелыми металлами $(\mathrm{Pb}$, $\mathrm{Cd}, \mathrm{Zn}$ и др.) и иными экотоксикантами вызывают геохимические трансформации эко- 
систем. Атмосферные поллютанты (в том числе и некоторые тяжелые металлы) вызывают проблемы со здоровьем при их проникновении в организм человека [1] и животных, а также способствуют развитию онкологических заболеваний. Взвешенные в воздухе субмикронные частицы (природного и антропогенного происхождения) могут переноситься при адвекции атмосферы и осаждаться, в том числе с атмосферными осадками, выступая ядром конденсации, на больших расстояниях от источника их образования.

В соответствии с глобальными циркуляционными условиями, над территорией Калининградской области РФ преобладает западный атлантический перенос воздушных масс. Соответственно, на окружающую среду исследуемого региона оказывает большее влияние деятельность индустриальных комплексов стран Западной Европы, нежели промышленных комплексов, расположенных на территории самой области и европейской части России. Показано [2], что поступление экотоксикантов за счет трансграничного атмосферного переноса превышает собственные выбросы локальных источников эмиссий в регионе в 5-7 раз.

В работе приведены результаты исследования составов (количественного, вещественного и химического) нерастворимых микрочастиц, поступающих с дождевыми осадками в прибрежные районы Калининградской области РФ.

\section{Материалы и методы исследования}

Изучение нерастворимых микрочастиц дождевых осадков в береговой зоне Ка- лининградской области РФ проводилось в 2019 г. За весь срок исследования было собрано и обработано 29 проб дождевой воды. Сбор проб производился на станциях, расположенных в береговой зоне Самбийского п-ва и на Балтийской косе (рис. 1).

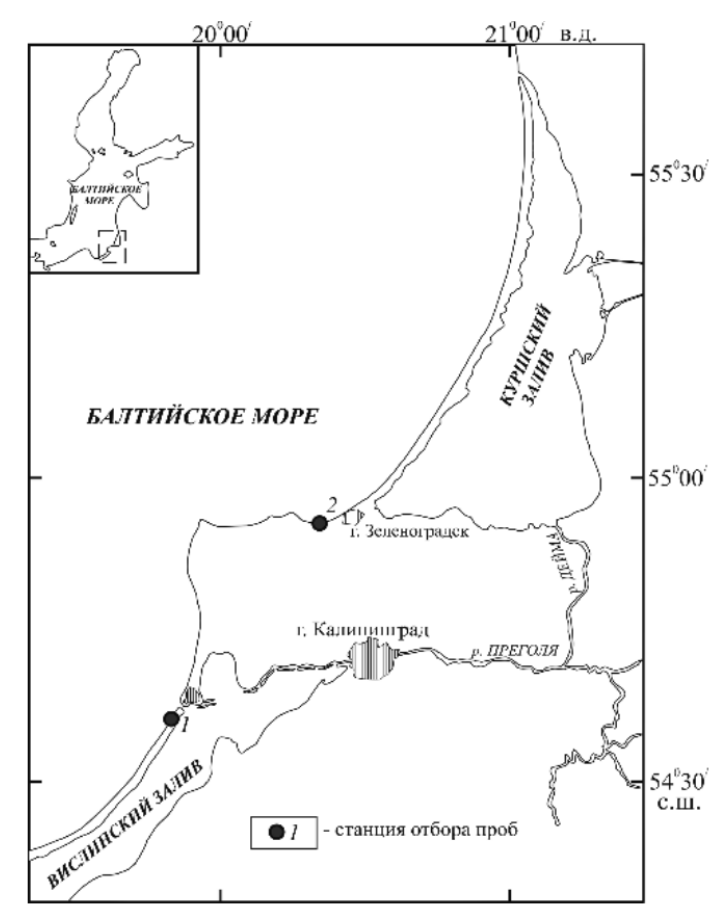

Рис. 1. Район исследования

Для сбора дождевых осадков использовали специальные приспособления (рис. 2). Устройство и принцип работы приспособления для сбора дождевых выпадений подробно описаны в статье [3].

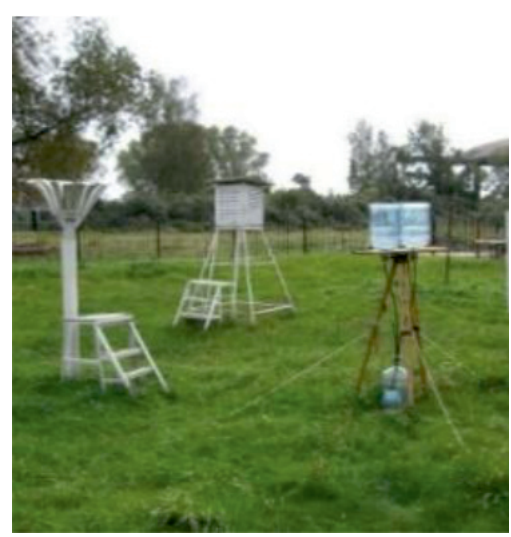

Рис. 2. Переносное спещиальное приспособление для сбора дождевых выпадений 1 - пластиковые сосудь-воронки; 2 - платформа; 3 -сливнье трубки; 4 - накопительная пластиковая ёмкость 
В зависимости от интенсивности и продолжительности дождевых выпадений, экспозиция по сбору проб составляла от 1 ч до 24 ч. Полученную дождевую воду доставляли в лабораторию. Осадочное вещество дождя выделяли на предварительно взвешенные лавсановые ядерные фильтры $\left(\mathrm{D}=47\right.$ мм и $\mathrm{D}_{\text {пор }}=0,45$ мкм) методом вакуумной ультрафильтрации.

При взвешивании на аналитических весах получали массу вещества на фильтре. Общую концентрацию нерастворимых микрочастиц (мг/л) рассчитывали по соотношению полученной массы вещества на фильтре к количеству профильтрованной воды.

Вещественный состав осадочного вещества дождей, выделенного на фильтре, и элементный состав отдельных микрочастиц изучался на сканирующем электронном микроскопе Vega 3 TESCAN (производство Чехия), оснащенного рентгеновским микроанализатором INCA Energy Oxford (производство Великобритания).

Для определения содержания тяжелых металлов в осадочном веществе дождей собранный на фильтрах материал (известной навески) подвергали кислотному разложению в тефлоновых бюксах в ультразвуковой ванне в течение часа при температуре 70 градусов Цельсия. Концентрации Al, $\mathrm{Mn}, \mathrm{Ni}, \mathrm{Cu}, \mathrm{Zn}, \mathrm{Cr}, \mathrm{Co}, \mathrm{As}, \mathrm{Sr}, \mathrm{Cd}, \mathrm{Mo}, \mathrm{Ba}$, $\mathrm{V}$ и $\mathrm{Pb}$ определяли методом атомно-абсорбционной спектрофотометрии на массспектрометре «Agilent 7500» в Институте океанологии им. П.П. Ширшова РАН. Для оценки качества анализа полученные результаты сопоставлялись с аттестованными значениями концентраций стандарта GSD-2. Стандартные ошибки определения не превышали $15 \%$.

\section{Результаты исследования и их обсуждение}

Количественное распределение. Содержание нерастворимых микрочастиц, поступающих с дождевыми осадками на территорию региона, изменялось в небольшом диапазоне - от 1.03 до 12,2 мг/л. Для всего периода исследования (апрель - ноябрь 2019 г.), их концентрация в дождевой воде составила в среднем 5,3 мг/л (по 29 определениям). В результате изучения количественного распределения микрочастиц в дождевой воде были выявлены сезонные изменения в их концентрации. Наиболее низкие значения концентраций (1,1-3,9 мг/л) были отмечены для весенних дождей 2019 г., а наиболее высокие (от 6,5 до 12,2 мг/л) - для летне-осенних дождевых выпадений.

Вещественный состав. Нерастворимые микрочастицы осадочного вещества дождя представлены биогенными, литогенными и антропогенными компонентами различной размерности от алевритовой (до 50 мкм) до пелитовой (<10 мкм). К крупным микрочастицам (до 50 мкм) относятся растительный детрит и волокна, а также пыльца и споры. Биогенная компонента микрочастиц доминирует в пробах весенне-летнего периода. Обрывки растительных волокон и пыльца, подхватываемые ветрами с поверхности земли, переносятся на сотни километров [4]. То есть в составе вещества дождевых осадков присутствуют биогенные частицы как локального, так и дальнего атмосферного переноса. Литогенная компонента представлена в пробах всех сезонов и в основном состоит из микрочастиц кварца (размером до 40 мкм) (рис. $3, a$ ). Кварц - наиболее распространенный минерал на побережье исследуемого региона, соответственно, его массовое присутствие в пробах свидетельствует о преимущественно локальном его переносе. Антропогенная составляющая нерастворимых микрочастиц доминирует в дождевых осадках, собранных в конце лета и на протяжении всей осени 2019 г. Антропогенная компонента представлена сгустками сажевых частиц, сферами сгорания (размером 3-8 мкм) различного элементного состава (рис. 3,6 ) и микрочастицами пепла. Образование и выброс в атмосферу сфер сгорания [5], происходит при деятельности тепловых электростанций (ТЭЦ), металлургических комбинатов и других индустриальных комплексов. Субмикронный размер сфер сгорания позволяет им переноситься в атмосфере воздушными потоками на значительные расстояния. Так как исследуемый регион находится на пути западного трансграничного атмосферного переноса воздушных масс, значительное количество субмикронных сфер сгорания в составе дождевых осадков может быть связано с деятельностью промышленноиндустриальных комплексов Западной Европы. Источниками эмиссий сажи могут являться как локальные источники, печные дымовые трубы жилого сектора региона, так и удаленные [6,7].

Химический состав. Результаты атомно-абсорбционного анализа о содержании химических элементов в пробах приведены в таблице. 


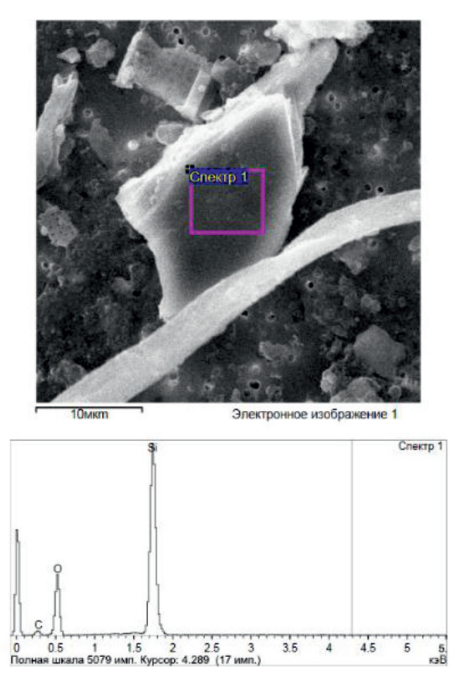

a)
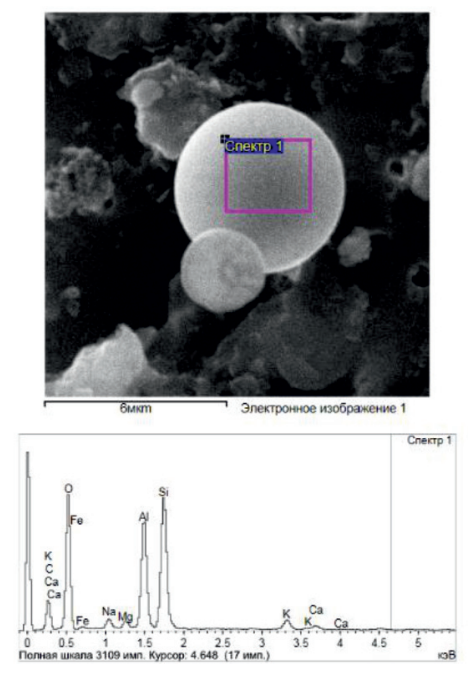

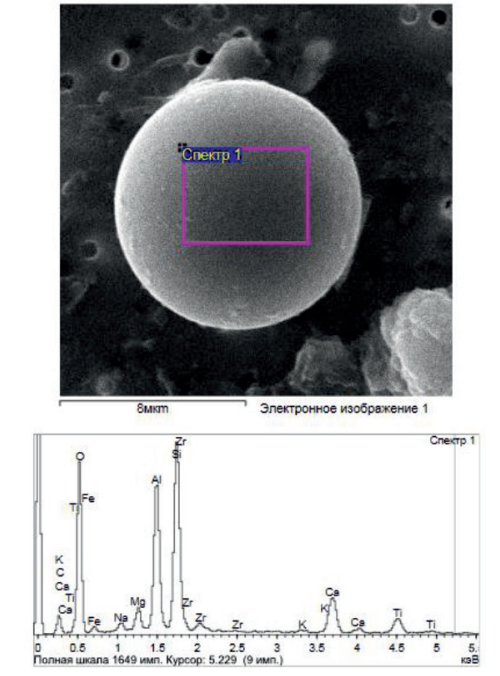

б)

Рис. 3. Элементный состав характерных микрочастии для разных сезонов 2019 г.: а) микрочастица кварцуа и растительное волокно; б) сферы сгорания

Содержание элементов в пробах

\begin{tabular}{|c|c|c|c|c|}
\hline \multirow{2}{*}{ Элемент } & \multicolumn{2}{|c|}{ Самбийский п-ов } & \multicolumn{2}{c|}{ Балтийская коса } \\
\cline { 2 - 5 } & $\begin{array}{c}\text { минимальное - макси- } \\
\text { мальное значения, мкг/г }\end{array}$ & $\begin{array}{c}\text { среднее значение } \pm \\
\text { ст. отклонение }\end{array}$ & $\begin{array}{c}\text { минимальное - макси- } \\
\text { мальное значения, мкг/г }\end{array}$ & $\begin{array}{c}\text { среднее значение } \pm \\
\text { ст. отклонение }\end{array}$ \\
\hline $\mathrm{Al}$ & $2542-20225$ & $8762 \pm 7031$ & $3113,3-22679$ & $9744 \pm 7592$ \\
\hline $\mathrm{V}$ & $6,7-35,7$ & $17,3 \pm 12,8$ & $16,2-46,2$ & $15,3 \pm 13$ \\
\hline $\mathrm{Cr}$ & $13,3-52,1$ & $32,6 \pm 15,9$ & $11,7-106,5$ & $53,9 \pm 37$ \\
\hline $\mathrm{Mn}$ & $35-609$ & $232 \pm 224$ & $45,4-621,1$ & $225,5 \pm 221$ \\
\hline $\mathrm{Co}$ & $1,3-9,4$ & $4,9 \pm 3,7$ & $0,9-9,7$ & $4,2 \pm 3,3$ \\
\hline $\mathrm{Ni}$ & $7,3-217,4$ & $73,9 \pm 71$ & $7,5-189,5$ & $84,4 \pm 67,4$ \\
\hline $\mathrm{Cu}$ & $31,9-119,5$ & $81,5 \pm 39,7$ & $23,3-210,4$ & $103,7 \pm 74$ \\
\hline $\mathrm{Zn}$ & $63,4-1120$ & $438 \pm 401$ & $62-1886,6$ & $672,3 \pm 659,4$ \\
\hline $\mathrm{As}$ & $1,4-6,5$ & $3,9 \pm 2,4$ & $0,8-8,9$ & $4,4 \pm 3,3$ \\
\hline $\mathrm{Sr}$ & $10,8-69,5$ & $34 \pm 23,2$ & $12-110,5$ & $49,4 \pm 39$ \\
\hline $\mathrm{Mo}$ & $0,6-2,8$ & $1,5 \pm 1$ & $0,8-2,8$ & $1,8 \pm 0,9$ \\
\hline $\mathrm{Pb}$ & $26,9-121,9$ & $73,3 \pm 36,8$ & $23,4-162,3$ & $90,7 \pm 58,8$ \\
\hline $\mathrm{Cd}$ & $0,7-9,2$ & $3,7 \pm 3,5$ & $0,6-6,2$ & $2,8 \pm 2,1$ \\
\hline $\mathrm{Ba}$ & $41,8-247,9$ & $94 \pm 86,6$ & $40,2-286$ & $127,4 \pm 97,9$ \\
\hline
\end{tabular}

Из таблицы видно, что концентрации элементов $\mathrm{Al}, \mathrm{Cr}, \mathrm{V}, \mathrm{Pb}, \mathrm{Ba}, \mathrm{Mn}, \mathrm{Cu}, \mathrm{Ni}, \mathrm{Zn}$, $\mathrm{As}, \mathrm{Sr}, \mathrm{Mo} \mathrm{и} \mathrm{Со} \mathrm{на} \mathrm{Балтийской} \mathrm{косе} \mathrm{выше,}$ чем их концентрация в осадочном веществе дождей на Самбийском полуострове. Исключение составляет содержание $\mathrm{Cd}$, концентрация которого выше на Самбийском полуострове.

Содержание химических элементов в составе нерастворимых микрочастиц дождевых осадков меняется в зависимости от соотношения различных компонент (литогенной и антропогенной). Известно [8], что скорости осаждения минеральных частиц достигают 2 см/с, а антропогенных 0,1 см/с, т.е. литогенные частицы достигают поверхности суши значительно быстрее, чем антропогенные. Из чего можно предположить, что антропогенные тяжелые металлы $(\mathrm{Pb}, \mathrm{Cd}, \mathrm{Zn}, \mathrm{Cu}$ и $\mathrm{Ni})$ поступают на территорию исследуемого региона в результате дальнего атмосферного переноса. 


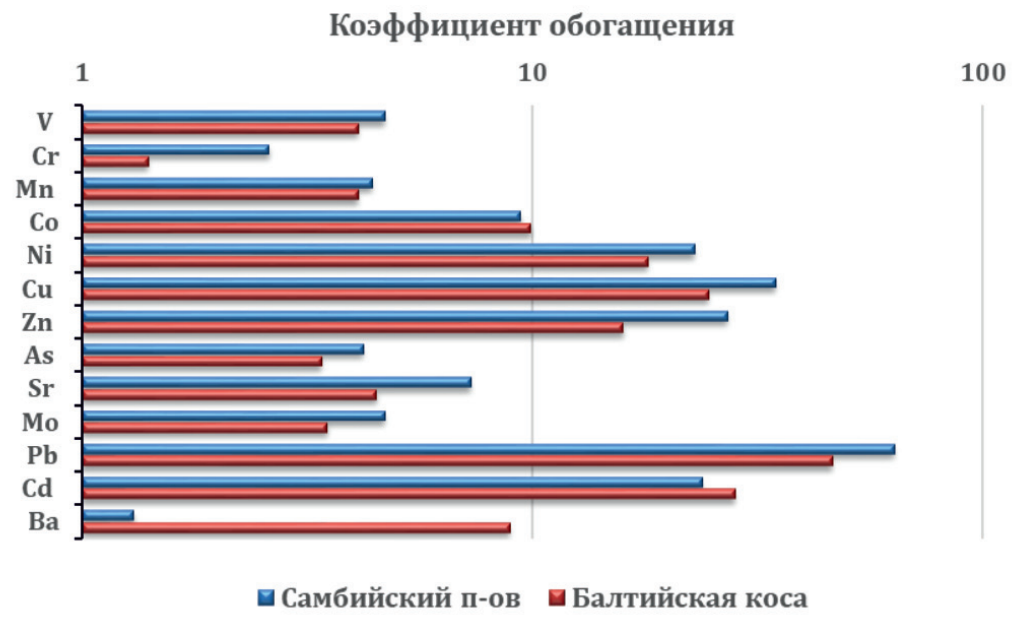

Рис. 4. Коэффищиенты обогащения тяжельми металлами осадочного вещества дождей Калининградской области РФ, относительно среднего состава верхнего слоя континентальной земной коры [9]

Для оценки роли различных источников тяжелых металлов в формировании элементного состава нерастворимых частиц в дождевой воде были рассчитаны коэффициенты обогащения $(K O)$ относительно среднего состава земной коры по формуле

КО = (Эл./Al) проба/ (Эл./Al) земная кора, $\left({ }^{*}\right)$

где Эл. и $A l$ - содержание элемента и алюминия, которое мы рассматриваем как индикатор литогенного материала, в пробе и в верхней части континентальной земной коры [9].

Расчеты КО позволили разделить химические элементы на две группы: 1 группа $($ КО < 10) - литогенного происхождения, т.е. характерные для земной коры; 2 группа $(\mathrm{KO}>10)$ - смешанного литогенного и антропогенного происхождения [10].

Коэффициент обогащения нерастворимых микрочастиц химическими элементами $\mathrm{Cr}, \mathrm{Mn}, \mathrm{Co}, \mathrm{As}, \mathrm{Sr}, \mathrm{Mo}, \mathrm{V}$ и Ва на Самбийском полуострове и на Балтийской косе меньше 10 (рис. 4), что свидетельствует о том, что эти химические элементы имеют главным образом литогенное происхождение. В то же время КО осадочного вещества дождей $\mathrm{Ni}, \mathrm{Cu}, \mathrm{Zn}, \mathrm{Cd}$ и $\mathrm{Pb}$ значительно превышает $10(K O \mathrm{~Pb}$ в Зеленоградске в среднем равен 64 , а на Балтийской косе - 46; $K O \mathrm{Cd}$ в Зеленоградске равен в среднем 24 , а на Балтийской косе - 28; КО Ni в Зеленоградске в среднем равен 23, а на Балтийской косе - 18 ; КО Сu в Зеленоградске - 35, а на Балтийской косе -25$)$, что свидетельствует об обогащении осадочного материа- ла $\mathrm{Ni}, \mathrm{Cu}, \mathrm{Zn}, \mathrm{Cd}$ и $\mathrm{Pb}$ из преимущественно антропогенных источников (загрязнение атмосферы выбросами промышленных предприятий и транспорта), переносимых на большое расстояние.

Корреляционный анализ. По данным корреляционного анализа выделено две группы взаимосвязанных элементов, поступающих от единых источников. Определена значимая корреляционная связь между концентрациями алюминия, марганца, кобальта, цинка, стронция и бария $(\mathrm{R}=0,87-0,98)$, что подтверждает их литогенное происхождение. Вторая группа взаимосвязанных элементов - цинк, хром, молибден, мышьяк и свинец $(\mathrm{R}=0,70-0,87)$, что указывает на их литогенное и антропогенное происхождение. Связь содержания ванадия, никеля и меди с содержанием других веществ отсутствует, что предположительно может свидетельствовать о множественности источников поступления данных металлов.

Для определения основных районовисточников были построены 120-часовые (5 суток) обратные траектории переноса воздушных масс к месту сбора дождевых осадков, при помощи модели HYSPLIT, доступной на сайте http://www.arl.noaa. gov [11]. По траекториям видно, что к моменту выпадения дождевых осадков в точках отбора на Самбийском п-ве и Балтийской косе воздушные массы в основном заходят с суши, проходя через города и промышленные центры европейских государств и мимо производственных и пустынных территорий области (рис. $5, a, \sigma)$. 


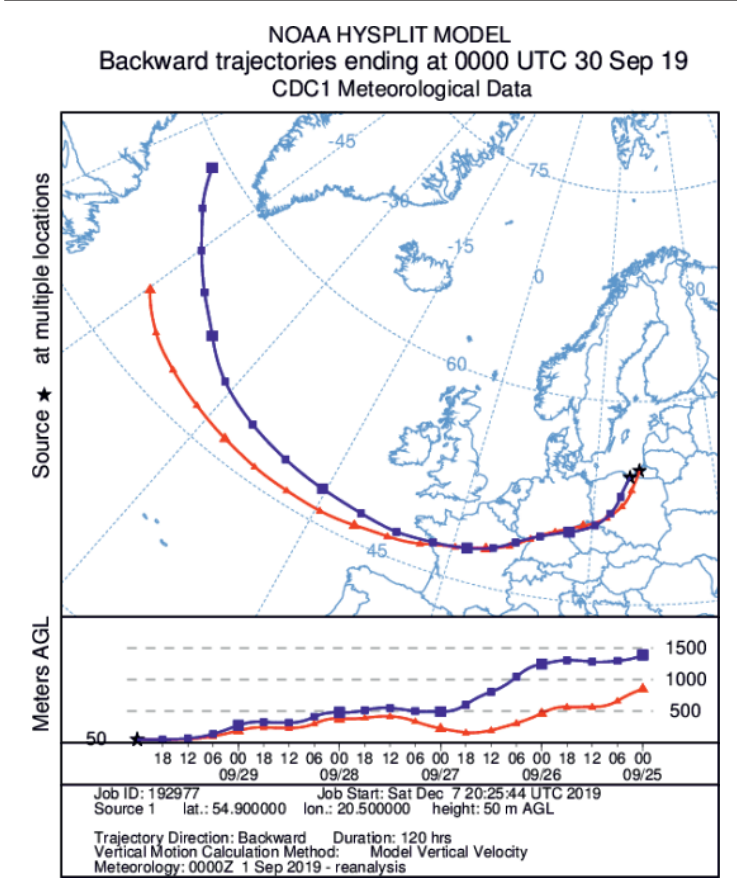

a)

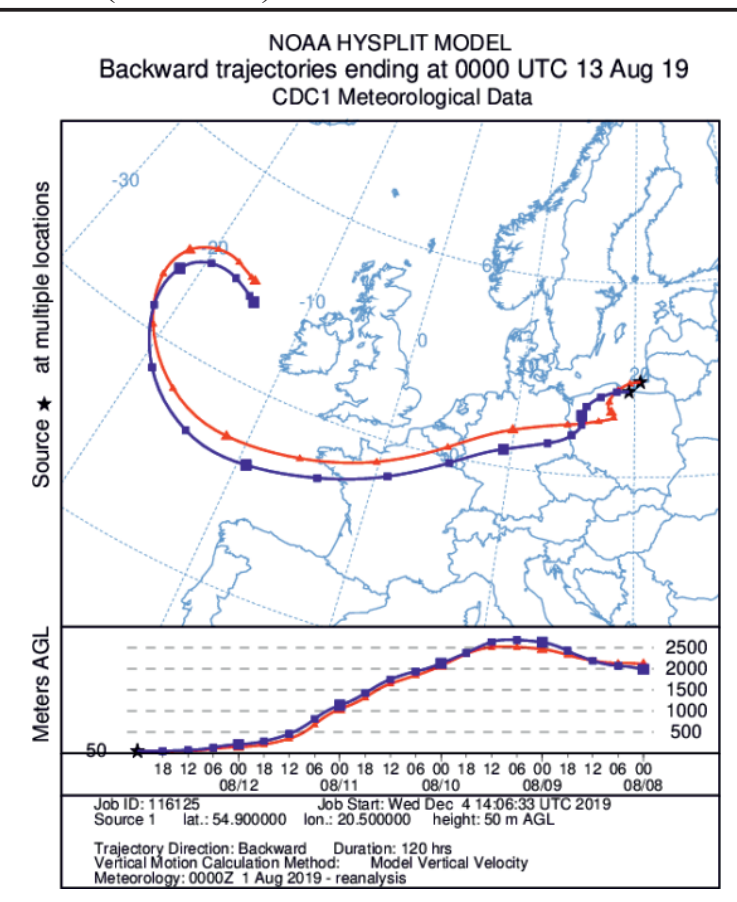

б)

Рис. 5. Траектории переноса воздушных масс в точку отбора проб.

а) максимальная концентрация в пробах $\mathrm{Ni}, \mathrm{Cd}, \mathrm{Cu}$; б) максимальная концентрация в пробах $\mathrm{Pb}, \mathrm{Cu}, \mathrm{Zn}$

Во время отбора пробы дождя с самым высоким содержанием свинца (121,9 мкг/г), меди $(119,5$ мкг/г) и цинка $(1120$ мкг/г) на Самбийском п-ове и свинца (162.3 мкг/г) и цинка $(1886,6$ мкг/г) на Балтийской косе (рис. 5, б), и с высоким содержанием никеля $(217,4$ мкг/г), кадмия $(9,2$ мкг/г) в осадочном веществе дождей на Самбийском п-ве, и отобранном на Балтийской косе (никель - 189,5 мкг/г, кадмий - 6,2 мкг/г, медь - 210,4 мкг/г и) (рис. 5, a), в эти точки поступили воздушные массы, ранее прошедшие над индустриальными центрами Франции, Германии и Польши.

\section{Заключение}

Авторами установлено, что средняя концентрация нерастворимых микрочастиц в дождевых осадках береговой зоны Калининградской области составила 5,3 мг/л. В количественном распределении и вещественном составе микрочастиц в дожде выявлена сезонная изменчивость. Наиболее высокие значения концентрации $(6,5-$ 12,2 мг/л) и доминирование антропогенной компоненты в составе осадочного вещества выявлены в дождях летне-осеннего периода, а наиболее низкие (1,1-3,9 мг/л), с пре- обладанием биогенной и минеральной компонент - для весеннего периода. Выявлено, что тяжелые металлы $\mathrm{Pb}, \mathrm{Cd}, \mathrm{Zn}, \mathrm{Cu}$ и $\mathrm{Ni}$ имеют антропогенное происхождение, a $\mathrm{Cr}$, $\mathrm{Mn}, \mathrm{Co}, \mathrm{As}, \mathrm{Sr}, \mathrm{Mo}, \mathrm{V}$ и $\mathrm{Ba}$ - литогенное.

Определена значимая корреляционная связь между концентрациями алюминия, марганца, кобальта, цинка, стронция и бария $(\mathrm{R}=0,87-0,98)$. Вторая группа взаимосвязанных элементов - цинк, хром, молибден, мышьяк и свинец $(\mathrm{R}=0,70-0,87)$. На распределение и состав нерастворимых микрочастиц дождевых осадков Калининградской области РФ оказывают влияние как локальный, так и дальний атмосферный перенос.

Экспедиционные исследования и химический анализ выполнялись при поддержке гранта РФФИ р_мол_а № 19-45-393007, анализ и интерпретация данных выполнялись в рамках госзадания ИО РАН (тема № 0149-2019-0013).

\section{Список литературы / References}

1. Lomova K., Valko M. Advances in metal-induced oxidative stress and human disease. Toxicology. 2011. V. 283 (2-3). P. 65-87. DOI: 10.1016/j.tox.2011.03.001.

2. Информационный бюллетень Управления Федеральной службы по надзору в сфере защиты прав потребите- 
лей и благополучия человека по Калининградской области «Особенности состояния здоровья населения Калининградской области в связи с влиянием факторов среды обитания в 2010 году». 2011. 46 с. [Электронный ресурс]. URL: http://39.rospotrebnadzor.ru/content/osobennosti-sostoyaniyazdorovya-naseleniya-kaliningradskoy-oblasti-v-svyazi-s-vliyaniem (дата обращения: 10.12.2019).

Information bulletin of the Office of the Federal Service for Supervision of Consumer Rights Protection and Human WellBeing in the Kaliningrad Region «Features of the health status of the population of the Kaliningrad region in connection with the influence of environmental factors in 2010». 2011. 46 p. [Electronic resource]. URL: http://39.rospotrebnadzor.ru/content/ osobennosti-sostoyaniya-zdorovya-naseleniya-kaliningradskoy-oblasti-v-svyazi-s-vliyaniem (date of access: 10.12.2019). (in Russia).

3. Чечко В.А., Курченко В.Ю. Методы исследований эолового материала в береговой зоне юго-восточной Балтики // Создание и использование искусственных земельных участков на берегах и акватории водоемов: труды международной конференции. Новосибирск, 2009. С. 175-180.

Chechko V.A., Kurchenko V.Yu. Research methods for aeolian material in the coastal zone southeast Baltic // Sozdaniye i ispol'zovaniye iskusstvennykh zemel'nykh uchastkov na beregakh i akvatorii vodoyemov: trudy mezhdunarodnoy konferentsii. Novosibirsk, 2009. P. 175-180 (in Russia).

4. Стародымова Д.П., Шевченко В.П., Сивонен В.П., Сивонен В.В. Вешественный и элементный состав приземного аэрозоля северо-западного побережья Кандалакшского залива Белого моря // Оптика атмосферы и океана. 2016. Т. 29. № 6. C. 488-492. DOI: 10.15372/AOO20160607.

Starodymova D.P., Shevchenko V.P., Sivonen V.P., Sivonen V.V. Material and elemental composition of surface aerosols on the north-western coast of the Kandalaksha Bay of the White Sea. Atmospheric and Oceanic Optics. 2016. V. 29. № 6. P. 507-511. DOI: 10.1134/S1024856016060154.

5. Guieu C., Shevchenko V.P. Dust in the Ocean. Encyclopedia of Earth Sciences Series. 2016. P. 203-208. DOI: 10.1007/978-94-007-6644-0_56-3.

6. Shevchenko V.P., Vinogradova A.A., Lisitzin A.P., Novigatsky A.N., Panchenko M.V., Pol'kin V.V. Aeolian and ice transport of matter (including pollutants) in the Arctic. Implications and Consequences of Anthropogenic Pollution in Polar Environments / R. Kallenborn (editor). Springer. 2016. P. 59-73. DOI: 10.1007/978-3-642-12315-3_5.

7. Byčenkiené, S., Dudoitis, V., Ulevicus, V. The use of trajectory cluster analysis to evaluate the long-range transport of black carbon aerosol in the south-eastern Baltic region. Advances in Meteorology. 2014. P. 137-694. DOI: 10.1155/2014/137694.

8. Лукашин В.Н., Клювиткин А.А., Бобров В.А., Дара О.М., Шевченко В.П. Химический состав аэрозолей Северной Атлантики // Океанология. 2018. Т. 58. № 5. C. 781-791. DOI: 10.1134/S0030157418050052.

Lukashin V.N., Klyuvitkin A.A., Shevchenko V.P., Bobrov V.A., Dara O.M. Chemical Composition of North Atlantic Aerosols. Oceanology. 2018. V. 58. № 5. P. 717-726. DOI: 10.1134/S0001437018050053.

9. Rudnick R.L., Gao S. Composition of the continental crust. Treatise on Geochemistry. V. 3. The crust. Amsterdam: Elsevier. 2003. P. 1-64. DOI: 10.1016/b0-08-043751-6/03016-4.

10. Chester R., Murphy K.J.T., Towner J., Thomas A. The partitioning of elements in crust-dominated marine aerosols. Chemical Geology. 1986. V. 54. P. 1-15.

11. Draxler R.R., Rolph G.D. HYSPLIT (Hybrid SingleParticle Lagrangian Integrated Trajectory) Mod access via NOAA ARL READY. Website (http://www.arl.noaa.gov/ready/ hysplit4.html). Silver Spring, MD: NOAA Air Resources Laboratory. 2003. 